\title{
Working with Parents to Support Their Disabled Children's Social and School Inclusion: An Exploratory Counseling Study
}

\author{
Elias Kourkoutas \\ Viviana Langher \\ Elena Vitalaki \\ Maria Elisabetta Ricci
}

\begin{abstract}
This article synthesizes the long-lasting counseling process of a family with a child suffering from a chronic illness. The provided intervention model draws on a series of principles from various theoretical approaches, namely systemic, psychodynamic, and resiliency. Family functioning and support is considered a catalytic parameter in assisting children with disabilities to fully develop their potential. This project is based on a family and child-centered integrative counseling model adopting the nonmedical conception of disability. Through the presentation of a case study of a couple who faced a critical situation in the life of their child, this article briefly describes the way the family dynamics were readdressed through this intervention counseling model. In addition, this work attempts to give a picture of the complex and confusing emotional states parents may go through when dealing with physical and psychological health-threatening situations and present guidelines for integrated counseling models.
\end{abstract}

Childhood chronic illnesses (CI) may be a source of difficulty to manage emotions and may create a series of practical problems for both the parents and the child. They can also cause a number of specifics limitations that have varying degrees of impact on the child and subsequently the whole family's psychosocial functioning (Dempsey, 2008). Specific medical symptoms and secondary physical or psychosocial problems arise from different conditions, varying in intensity and the need for treatment (Kourkoutas, Georgiadi, \& Plexousakis, 2010).

Differences in the way the child and its family experience the CI depend on the age the symptoms manifest, the developmental period of the child, the type and extent of medical support needed, the degree of health and life-threatening risk, how noticeable the impairment/disability is, the parents' personality or psychic organization, the family structure and couple's life, and

Elias Kourkoutas is a clinical child psychologist. He is a professor of Psychology at the University of Crete in the Department of Primary Education.

Viviana Langher is a professor of psychology at the University of Rome, School of Medicine, La Sapienza.

Elena Vitalaki is a developmental psychologist at the University Of Crete.

Maria Elisabetta Ricci is a lecturer of clinical psychology at the University of Rome.

Correspondence should be addressed to Elias Kourkoutas, Professor of Psychology, University of Crete, Gallou, 74100, Rethymno, Greece. E-mail: hkourk@edc.uoc.gr 
the wider family attitude and the social perception of the disability (Drotar, 2006; Sperry, 2014). Therefore, the requirements and the type of intervention may differ depending on the specific family dynamics, the parents' and child's coping and self-defense mechanism, as well as on the child's developmental stage (Wilson, 2003).

\section{FAMILY ISSUES AND APPROACHES IN THE AREA OF DISABILITY AND CI}

In some cases, the severity of a child's CI and the high degree of the health risks may have a disintegrating or traumatic effect on the family, the parents' relationship and parental skills/identity; such situation might trigger unprocessed feelings related to the history of their relationship with their own parents and their family role as children. In fact, many theorists and counselors prioritize a trauma theory model in conceptualizing and working with the families' reactions and the child's development when it suffers a chronic illness (Wilson, 2003) stressing that in some cases, intervention should assume a parent-child or family therapeutic orientation.

Families of children with disabilities develop a variety of reactions across a spectrum. At one end of the spectrum, disorganized and disintegrating or extremely anxious and trauma-based reactions may be found; on the other end are positive, accepting, or life-affirming reactions (Dempsey, 2008) that might also give testimony to strong internal resources or even defenses and resistances to traumatic, hostile or ambivalent feelings related to their children's problems (Frick, 2000).

Parental reactions towards a child with CI seem to be the result of mixed ambivalent or conflicting emotional states and effects that vary with the time and the kind of social, emotional, and economic experiences the family is going through (Seligman \& Darling, 2008), as well as parents' psychic organization. Extreme reactions (e.g., avoidance of a caring involvement, family abandonment, and divorce, or even overidentification with the child's "healthy part" and search for normalization neglecting the child's real needs, ongoing grief, and so on) can also be detected. In fact, many of these parents might internally struggle with strong negative emotions towards the chronic illness or experience intense guilt mixed with hate towards the vulnerable child and reluctance to express feelings which can lead to inappropriate responses (Wilson, 2003; Kourkoutas, 2008). Although, many parents of disabled children declare they have found a new meaning in life after the birth of a child with a disability, most of them have to sacrifice important sections of their life (e.g., leisure, personal or professional development, harder work), which can create significant internal or interpersonal conflicts (Vickers, 2006). In fact, Vickers in her study on mothers' experiences of parenting children with a chronic illness showed that the whole maternal sample reported their tremendous struggle balancing work and home life, especially with the enormous physical and emotional burdens placed upon them as a result of their care responsibilities. The mothers in this study reported the "ongoing and recurring grief" they experienced for their child with the disability that others usually were not aware of. The repression or the inadequately processed emotional experience of having a child with a chronic disability can result in grief and denial of the full course of mourning, or to bounded grief, grief that is not enabled (Vickers, 2006). 


\section{MEDICAL VERSUS RESILIENT, CHILD AND FAMILY-FOCUSED INTERVENTIONS}

Extremely medicalized specialist-centered approaches have been criticized as not being meaningful for families of children with disabilities focusing mainly on the external aspect of the CI management or superficial approaches that might be helpful in at first, but leave untouched many of the family and parents' internal issues and concerns (Walsh, 2006; Crown, 2009; Kourkoutas, 2009). New theoretical and epistemological models have been raised in childhood psychopathology and disability, challenging the conventional perceptions of the disability as solely an inherent individual deficit or an issue for experts issue (Zipper \& Simeonsson, 2004).

Abandoning the pathology- and deficit-centered model for families of disabled children, contemporary counseling interventions tend to be comprehensive, flexible, multimodal, eclectical, and integrative prioritizing a supportive or therapeutic dimension focusing both on the practical help of parents and on the reframing of family psychic dynamics (Smith, 2013). They also tend to be family- and community-based, emphasizing a partnership approach, and thus more meaningful for families and professionals in a plethora of sections and levels, without, nevertheless, failing to individualize each family member's needs, difficulties or resources (Cramer, 2000; Frick, 2000; Kourkoutas \& Raul Xavier, 2000; DeV. Peters, Leadbeater, \& McMahon, 2005; Walsh, 2006; Schmidt, 2010). In fact, available data prove the efficacy of such holistic and partnership approaches in the treatment process involving families of children with various forms of disabilities and disorders (Carr, 2009). Such radical modifications, presupposing paradigmatic shifts in the intervention area, have not always been successfully implemented due to the lack of professionals' adequate training and to the inflexibility of existing systems of care in a number of countries. Many academic and training curriculums, services for families and children, and classification systems are still under the dominance of the medical paradigm (DeV Peters et al., 2005).

\section{AN ECOSYSTEMIC PSYCHODYNAMIC AND RESILIENT WORKING MODEL FOR FAMILIES AND CHILDREN WITH DISABILITIES}

In this article, we present a working model aiming at supporting families through the course of their child's illness/disability from the time of diagnosis through adulthood. The proposed model of intervention focuses on reducing the effects of various traumatic experiences of families of a child with a life-threatening illness. The main scope of the model is to help all family members avoid developing maladaptive or dysfunctional coping patterns during critical phases. The model essentially focuses on providing an array of supportive techniques and assistance in order to help families reframe and handle the traumatic experiences and thus regain control of their lives.

This model, principally based on a theoretical level, on psychodynamic, ecosystemic, and resilience (strengthening, empowering) approaches, draws also from disability research and evidence-based practices for children with chronic illnesses. More specifically the following theories and approaches are the key theoretical references of our working model: (a) attachment and contemporary psychodynamic /relational theories (Emde \& Robinson, 2000; Wilson, 2003; Maroda, 2010; Altschuler, 2011); (b) systemic approaches (Fraser \& Galinsky, 2004; Schmidt, 2010); (c) trauma related theory and models for CI (Smith, 2013); (d) risk theory and research on 
family factors /family dynamics in the area of disability and chronic illness; and (e) resiliency based individual interventions for the child at risk (focus on fostering child's psychosocial skill) (Hart \& Blincow, 2007).

Finally, the model emphasizes partnership work by all involved professionals. Counselors' work in cooperation with hospitals, medical centers, medical staff, school seniors, school teachers, special educators, school counselors, and other professionals in order to buffer contextual or individual risks and facilitate children's social and school integration (Sperry, 2014). The resiliency perspective emphasizes the importance of developing strategies to enhance children's inner capacities. Resiliency is not considered a static possession of specific skills. Adequate parenting can foster resiliency solutions (Walsh, 2006). The resilience oriented individual treatment can also help less skillful children or children impaired by dysfunctional parenting to develop their own capacities or learn new coping skills (Walsh; Hart \& Blincow, 2007; Seligman \& Darling, 2008). Moreover, resiliency, within our framework, is related to relational processes emerging between different involved partners who attempt to co-create and share new meanings to the parents' painful experiences. Professionals should be able to listen to parental narratives and reframe the way they are experiencing their child's illness and the emotional meaning they give to it.

On a practical level, the model is integrative and eclectic, using an ample array of techniques (e.g., psychodynamic, supportive, solution-focused, play, drawing), even though the main key theoretical reference in the treatment process remains a psychodynamic, individual and family therapy approach. This model highlights the importance for parents and children at risk, of developing adequate coping skills, working on internal issues that might hinder their own resources and potentially lead them to dysfunctional thinking and acting. Particular emphasis is given to the critical periods of the child's development, such as hospitalization, schooling, social inclusion, transition to adolescence, and professional training.

More specifically, the key guiding principles of the working model are the following: (a) emphasis on "preserving" the family and "containing" parental anxiety, distress, depressive, and painful feelings by providing a trusting and supportive therapeutic relationship especially during critical periods (e.g., hospitalization, operations) (Emde \& Robinson, 2000; Frick, 2000; Wilson, 2003; Crown, 2009; Altschuler, 2011); (b) understanding parents' "acting out" or problematic reactions; (c) working with parents', children's, and other siblings' negative emotions in order to enhance new relational and communicational patterns within the family; (d) taking into consideration the parent's knowledge of the child; (e) enhancing parental rearing capacities by assisting them in developing new parental skills when it is necessary; (f) training and guiding parents in various areas of their child's psychosocial development, helping them give sense to what sometimes is experienced as a disorganizing, unbearable crisis, and focus on practical solutions; (g) guiding and coaching parents in order to adequately deal with their child's emotions and behaviors in everyday life or during critical situations; helping them better understand their child's emotionally distressing states, processes, and developmental needs (Power \& Dell Orto, 2004; Hart \& Blincow, 2007); and (h) providing information and mediation among all involved rehabilitation services, such as physicians, hospital counselors, and other paraprofessionals.

More specifically, regarding family treatment and parental "therapy" issues, Marianne Frick's theorization referring to Winnicot's, Benedek's, Stern's, and others' work on parental and mothering roles is of critical importance. Frick (2000) explores, in detail, the technical issues related to both the individual and family aspects of the work with the families of children suffering from 
various psychic or somatic difficulties. She discusses the different levels and directions of this work (e.g., moving from conscious or practical to deeper or subconscious levels of family or couple life), the positive aspects (e.g., providing the whole family and each family member with a framework and space to re-work disturbing emotional burdens or neglected family issues and secrets), and the technical requirements and difficulties (e.g., combining both family and child treatment, involvement of different professionals and therapists, intense countertransference situations due to parental or projective reactions) or adjustments that professionals are obliged to realize. She, as other authors, concentrate on the importance of involving parents, as active partners, in their child's treatment and on the strong feelings of guilt, shame, or paralyzing depressive effects that are often activated in such cases. She also concentrates on parents' struggle to maintain a psychic balance and find meaning in their life and in the parental role that might be expressed in aggressive or depressive ways, as they lack the skills to become resilient enough. Professionals should be able to recognize, behind parents' aggressive feelings or their "humiliated" fury towards specialists, the (masked) feelings of shame, guilt, loss of hope, and pain for their child's future (Frick, 2000; Kourkoutas, 2012). Otherwise, professionals might feel denigrated or aggressed by the parents or react by identifying with parents' angry feelings and, thus, enter into conflict with other professionals or contesting diagnosis.

In fact, one of the main challenges for professionals in this area is their ability to move from intrapsychic to systemic issues and vice-versa, a job that requires that professionals/therapists have achieved personal work and high quality training in psychodynamic, systemic and psychology of health issues. This should be an essential component of the professional training of specialists who work in this area in order for them to avoid being trapped in dysfunctional or distorted counter-reactions (e.g. identifying or counter-identifying with "problematic" aspects of the parents or over-identifying with the child with CI, experienced as a victim).

\section{METHODOLOGICAL ISSUES ON THE CASE STUDY RESEARCH VALIDITY AND STUDY GOAL}

This article draws on an individual case study to illustrate the ways in which families of children with CI have experienced different degrees of distress and social-emotional difficulties with the risk of impeding the child's (social-emotional-learning) development. This small scale qualitative study was developed as part of a wider research-intervention project on resilience, involving parents and school staff to support children at risk. Data were collected during counseling sessions with all family members and the school staff in later years by a research counselor who assisted (participative method) in these sessions throughout. Notes were taken during and after the sessions focusing on the families' experiences and the way counseling work was conducted. An academic counselor operated as external supervisor with regular meetings in order to discuss the various issues of the counseling work with parents and teachers. As for the number of counseling sessions with parents, the number varied between 10 and 15 each year depending on the critical situations. ${ }^{1}$

The case study analysis can provide useful insights regarding the technical information in the counseling method, as well as in- depth description of emotional processes and mechanisms employed by parents or children in order to cope with painful feelings or intolerable realities. 
This article attempts to call attention to the sophisticated multilevel counseling manipulations and handlings required in order to help parents and the whole family overcome these critical situations or conflicting realities they face, on affective, psychological, interpersonal, and practical levels.

\section{A CHILD WITH A BRAIN INJURY: FAMILY DYNAMIC'S ANALYSIS AND CHALLENGES OF THE COUNSELING INTERVENTION PROCESS}

This intervention was provided by two counselors working in the area of high incidence disability and with families at risk in a psychotherapeutic perspective within a university hospital context. The problems and challenges which this family had to deal with are similar to the intra- and extrafamilial difficulties and many middle class parents face when dealing with the high incidence of childhood chronic illness. The work with these families may be short, lasting just a few months, or very long, lasting several years. Its frequency and intensity also varies according to a number of parameters related to the child's and family's emotional and social problems, and the family's request for assistance.

Counselors on this team were trained in a psychodynamic and systemic perspective and work essentially in the area of disability, fostering a flexible and holistic approach, based on a family and relational centred model of disability (Emde \& Robinson, 2000; Schmidt, 2010; Smith, 2013). The possibility of "supportive supervision" also existed in order to help the counselors to better deal with the intense feelings elicited by critical family situations or ambivalent and excessive requests.

The case of P. has also been presented in another paper in which a detailed analysis of risk and protective factors has been conducted in order to explain P.'s gradual successful school and social integration, as well as her parents' effective dealing with the perpetual critical situations they experienced (Georgiadi \& Kourkoutas, 2010).

P. is a girl, almost 7 years old now. Her mother is Greek and her father's origin is Italian. At the age of 7 months, P. suffered a stroke that left her with mobility problems and the left side of her body was seriously impaired (hemiplegia). It caused considerable delay in her walking but did not affect her cognitively. The continuous hospitalization over the years along with a compromised immune system and a stenosis in the main arteries of the brain, after numerous, constant and usually painful examinations, prevented her from fully developing her psychosocial skills, and for about three years, she did not come into contact with other children. There was also the distressing need for care by her parents for her protection against germs/viruses and their insistence on avoiding areas where children gather.

At the same time, the family's high level of anxiety about the acceptance and adaptability to the new situation, and the insecurity for the long-term and irreversible effects on the health and psychology of their child, was worsened by the lack of a clear medical diagnosis on the nature of the cause (external or inherent) of the illness that continued for a long time. Moreover, the doctors were not sure about the long-term effectiveness of the therapy they followed, and consequently a couple of critical and anxiety provoking dangerous situations which developed, were controlled and reversed due to timely counseling intervention.

It was at that moment that P.'s mother decided to consult a specialist, as she was feeling depressed and distressed, not only with how to deal with the unbearable feelings regarding her 
child's condition but also about how to defend herself against her husband's unexpected violent reactions and tantrums. Actually, just after his child's stroke, her husband went through a very confusing phase expressing intense anger and rage against his wife accusing her that "she was the one who wanted this child." Overwhelmed by the requirements of his daughter's physical conditions and by the shock of seeing a healthy and joyful infant transforming into a "mutilated creature" (as he mentioned in one of his first sessions), he felt powerless, despaired, and incapable of accepting this new reality. The mother, as well, felt that the family was very close to catastrophe and an irreversible crisis. She became heavily involved in the counseling process and she believed afterwards that the supporting relation to her therapists was crucial in helping her confront this extreme situation. She convinced her mother and her mother-in-law to attend a series of sessions, because she believed they were also distressed and in need of help and support to deal with the everyday responsibilities of the child's care in a more decisive and creative way. Although both grandmothers initially responded very positively and calmly, one of them regularly asked for support, as she was feeling depressed, anxious and physically exhausted.

Progressively, P.'s mother and mother-in-law took complete responsibility for the child's daily care, without expressing any kind of anger against the husband. They were all convinced that he was "immature" and incapable of being fully involved in the child's care.

The father participated in some of the sessions but refused to get involved in the counseling process on a regular basis. The initial session immediately focused on helping him feel comfortable and talk about this unbearable internal reality of seeing his daughter in this state, as well as to face the possibility of death. This initial counseling phase was hard to handle. In fact, during this first phase, counselors experienced intense unpleasant and controversial feelings towards the father. Though, during the supervision process, they became aware of their mixed feelings of anger and fear toward the father which led them to realize how the father was feeling deep inside. In fact, the father was overwhelmed by unbearable emotions and the fear of death, as well as of a negative attitude towards any affective engagement in the counseling process. As it was revealed later, he was struggling inside him for his autonomy against an overprotective maternal figure. However, after an initial very defensive attitude against the counselor, he did not stop crying during the whole sessions. He was limited to continuous "emotional acting-out" without being able to verbalize his deep concerns or to accept any treatment or any organized plan for his daughter. As his wife stated, he was in a constant state of mourning and intense fear of death for his daughter, but also for himself. Unable to control his life, he continually expressed his death fears and his denial of his child's illness by attacking his wife.

Usually, these preliminary sessions are devoted to helping parents name or define, and verbalize their confused and painful feelings regarding the physical disabilities and the health or death risks of their child. Indeed, during this phase, it is important for parents to learn how to articulate their unbearable negative emotions and distress and avoid acting them out in their relationships with others with disorganized, harmful, or even destructive behaviors. This way also helps them become more conscious and aware of the other members' distress or conflicting emotions.

A significant moment in the work with the father was when he referred to his mother's contribution in dealing with the many challenges the couple was facing with P's illness. He revealed that he had always had a very difficult relationship with her, as she was an overprotective, "interfering" and "controlling" mother. He "left his own country to distance himself from her" and achieved self-autonomy. He would never have thought that he would be so close to her again. $\mathrm{He}$ 
voiced his sadness about that in a very touching way. Some sessions later, referring to his mother again, he admitted that he felt much more comfortable now, although he was not conscious of how "controlling" he was towards his wife and his daughter.

P.'s father believed that he was helped by the initial few sessions, and he felt quite relieved of his intense guilt and confusing feelings. In addition, he stopped being so aggressive or enraged toward his wife and himself (he used to beat his head against the wall); his anger had probably transformed into panic attacks manifested during this period, reflecting his deeper distress and feelings of pain. Counselors were convinced that deep inside P.'s father was a feeling of guilt at not being able to provide his mother with a "healthy" child; they did not, however, manage to work on these feelings. At the same time, his wife became more aware of the intense conflicting emotions her husband was experiencing and thus became more accepting of his limited involvement.

In this phase, counselors should be able to create the proper relational environment to help parents talk, without feeling guilty, about their ambivalent or negative emotions regarding other members of the family or even about the anger they often experience while caring for their child. Counselors should manage to help parents avoid being trapped in destructive and dysfunctional interactions and communication by respecting and acknowledging everyone's own reality and by allowing them to reveal their deeper concerns, doubts, fears, and anxieties. They should also be very careful how they respond in situations where a parent seems distant, trapped inside himself or even indifferent or when a parent accuses the other one of being irresponsible. Counselors should go beyond superficial symptomatic reactions and dysfunctional responses and help parents recognize the amount of responsibility or involvement that every family member has.

When parents are helped at the emotional and practical level, they usually become more capable of managing their everyday life. By progressively handling their negative emotions, they regain control of their internal reality and thus become more capable of facing the external stressful situations. After health conditions are stabilized, concerns and distressed fantasies about the child's future, the child's likelihood of living a regular life, of making friends or of being loved and accepted are more likely to occur.

In P.'s case, the greatest stress for her parents, besides the stability of the medical problems, was the question of their child's nutrition. The daily feeding created great stress and anxiety and the father gradually became involved in this procedure. The mother admitted to the psychologist that during the first few months she was overwhelmed by fears of death and worries for the life of her child. Meanwhile, she had to face her husband's anger and attacks, claiming that he didn't want the child, that she ruined their life, and that they would have been better off without her. The issue of physical therapy and rehabilitation was second in importance due to her feeding problems. The practical guidance of the psychologists was impossible to follow. In time and with the support of the extended family, the couple was able to accept and adapt to the existing situation with less anxiety and fear of the death of their child.

At the end of the second year, after going through a long period of confusion and panic attacks, the father finally decided to see another member of the team alone. This time, during the sessions, he was much more inclined to talk about how he was feeling, about his intense frustration and inability to help his wife; about how guilty he had felt and how relieved he was now, as his wife and his mother took full responsibility for the child's care. He also expressed his (in fact unrealistic) fears of losing his job, but mostly his disappointment at not being able to pursue his scientific career in the United States, under these conditions. 
The love of the father for his child was incontestable, despite his limited involvement in the daily routine. In fact it is important for the counselor to recognize the true feelings and what is hidden behind the withdrawn or aggressive and oppositional attitude of one or the other parent. It is noteworthy that in childhood illness and disability, except for cases of obvious child neglect or abandonment, many parents who seem to be superficially rejecting their child, in reality are not capable of accepting the child's illness, the probability of death or body damage. In this sense, it is believed that the father was helped to be better understood and appreciated by his wife in his attempt to deal with the painful situations and unbearable feelings. Actually, the wife, for long periods of time, felt abandoned and rejected and only with the counselor's help she felt progressively "stronger" and more aware of how to manage the couple's crisis situation in everyday life.

When the child was three, a kind of balance was achieved despite the exhaustion, the stress over feedings, the anxiety about the way she would walk and her many falls. The negative climate was somewhat lessened, with the father becoming more involved but still offering little essential help on the issue of feeding.

At the end of the third year, the doctors judged that the situation was under control and decided that the medical tests and medical care should decrease. During this period, the family had shown great strength and power in dealing with the reactions and refusal of their child concerning her visits to the hospital. The medical and insurance coverage was adequate and the family was not financially burdened.

At the beginning of the fourth year P., had gradually started to come into contact with other children, despite her problems concerning her mobility and flexibility in language expression. Despite these problems, she managed to familiarize herself with the other children and play together with them.

The next year was somewhat similar with fewer medical examinations, substantially fewer therapies and P. socialized better with other children. Greater emphasis was given to physical therapy, while the psychologists reassured the family that their child possessed high intellectual capacities, in spite of the obvious delay in her speech development. Her father's stress became less, his panic attacks decreased, even though he remained deeply concerned about his daughters' feeding, his involvement in her daily life remained minimal. The child showed improvement in her walking (always limping and with the aid of a cast) and psychologically, she exhibited high levels of energy and signs of self-sufficiency. Meanwhile P. attended a program at a specialized day-care center twice a week, while the mother's walks with her child to parks and recreational areas became more frequent. The mother felt comfortable with the social environment without feeling shame or embarrassment.

During this period, the counselors had to deal with the issue of the overprotective parental attitudes towards P. as well as with her eating behaviors that were very difficult for the family to handle. Meal times were characterized by great stress and pressure for the child who refused to eat. While P. sat in front of the TV, the whole family gave "circus-like" performances, using different tricks in order to "fool" her and persuade her to accept her food. Even though her weight was not satisfactory, her health was not in danger.

The great change came about when the family decided to visit the mother's hometown and her extended family. P. and her mother stayed there for two months, but the experience of this visit was positive for everybody. P.'s acceptance by the extended family was amazing, according to the mother. P. became more autonomous and capable of dealing with children and food. During 
this phase, counselors supported the family in deciding to make this trip, as the father was very anxious when the child was away from the regular hospital center. In addition, counselors had to help parents handle the extreme and irrational fears of death related to her nutrition. Parental tress about the food and was obviously related to fears of death.

Counselors expressed their belief on how obvious was for the parents to associate the issue of dead with the problems of feeding. They also stated that, although, it was natural for them to worry, their anxious and overprotective attitude towards the child regarding the food was quite alienating for P., as it progressively became a strategy to gather the whole family around her. Parents were encouraged to be less anxious and more firm towards P. in issues of feeding. The mother was much more confident in her daughter but somehow, also very stressed. One of the grandmothers and the father were very reluctant to follow the counselors' advice about the food rituals. Positive progress was realized on this issue during this time, as the parents gradually became aware of the strategies they should apply in order to make P. eat better. More highly therapeutic changes came about on the issue of food during the holidays. Through her interaction with other children, P. expressed her desire to eat. She attempted and managed to eat alone, she sat at the table with her cousins and the other children and she imitated their ways. She shared food with the others, tried new tastes and she tried new foods such as milk that she had never tried before. The extended family and telephone support with the counselors encouraged the mother and mostly the grandmother to trust P. with food and to display less stress, while expanding the meal choices. The return to their home was characterized by considerable improvement regarding P.'s socialization and ability to eat in an autonomous way.

P.'s mother as well as her grandparents continued to have regular contact with counselors. The father, as it has already been pointed out, had developed an ambivalent position with the counselors apparently transferring to them the same ambivalent and conflicting feelings, he displayed with his daughter's illness. As he admitted a year later, in a very emotionally charged session, "he adores his daughter but he hates her illness." He was torn between these two extreme positions signifying his inability to overcome the profound mourning of the "healthy" child he never had (Smith, 2013).

Gradually, P. became more aware of the difficulties she had managing her body and the differences with other children's bodies. An important moment at that time was when the family had to explain to her what was special about her body and why she could not walk well. With the counselors' support, the family and especially the mother, took the initiative to start talking to her about her medical condition and at moments of great ease with her daughter, to talk about the stress, the fears and challenges that the family had to deal with during various critical periods (e.g., hospitalization, operations), as well about the love both parents have for her. This activity continued during the counseling sessions, when the mother was encouraged to speak about her daughter's illness and her own painful experiences during P.'s hospitalization, by directly talking to her. A series of sessions were devoted to this procedure which clinically is considered to have a beneficial effect on both parents and children when it is controlled. In fact, by expressing and sharing together the extreme emotional experiences they have been through, parents and children seem to come closer.

The work of the child's therapist consisted, with the contribution of the other professionals, of strengthening P's psychosocial skills and helping her to be better adjusted in social and school contexts. 


\section{WORKING TOWARDS SCHOOL INCLUSION}

In the period that followed, in the fifth and sixth year of the intervention process, the counselors' work essentially focused on addressing the risks and the new challenges regarding her socialization and school inclusion.

Building a collaborative partnership between parents, teachers, professionals and counselors seems to be essential in order to provide the child, family and school personnel with the necessary emotional and instructional support so the student's inclusion at school can be successfully coordinated and achieved (Georgiadi \& Kourkoutas, 2010). Counseling guidance for teachers focusing on handling emotional difficulties and peer relationships of the pupil with CI was also important in order to provide an optimal environment for the child's school inclusion and academic achievement. Counselors suggested teachers to be attentive to P's social needs without being overprotecting towards her and setting boundaries on her behavior, whenever they believed it was necessary. The teachers found that the successful managing of their distress, concerns, and even prejudices of some of their colleagues regarding the child's medical needs and academic success was due to the counselors' help and guidance. Apart from the individual sessions with the classroom teachers, group meetings have been effectuated with other school staff in order to provide necessary information or guidance on the child's capabilities and school inclusion challenges. As some of the school staff revealed, "they were concerned and negative the first time P. came to their school". Both group meetings and individual sessions "helped [them] to overcome some of those concerns and prejudices" often due to the "lack of knowledge or to "a distorted idea of chronic illness and of our responsibilities".

\section{DISCUSSION}

The quality of parental relations with the child with $\mathrm{CI}$ is fundamental for the design of a comprehensive intervention (Taylor, Gibson, \& Franck, 2008). In many cases, parents unconsciously or unintentionally develop various forms of partially or totally dysfunctional relational or rearing patterns. These patterns may have to do either with a parent's deficient parenting skills or with unbearable emotions and distress leading to dysfunctional rearing patterns (e.g., anxiety, overprotectiveness, anxious aggressive-controlling, ambivalent attachments) and couples' conflicts (Seligman \& Darling, 2008).

In the case of P., the strong and mature personality of the mother, her commitment to and investment in the counseling work helped her further reinforce her positive attitude towards her child, self and child's level of self-confidence, despite the major quarrels and emotional frustrations she was experiencing with her husband. Moreover, the counseling sessions helped the mother overcome her fatigue, and comprehend some of her child's behavior, as well as better accept her husband's reactions and hence stay by his side during critical periods.

Overall, the counselling work essentially focused on helping parents face the risks of family fragmentation and overcome critical periods of high stress related to their child's life-threatening conditions. Counselors also helped parents better support their daughter during her schooling by mediating between classroom teachers, special education teachers, and the family, as well as by intervening when necessary to resolve conflicting school situations. Without a doubt, the way in which supported teachers can work with students with disabilities or vulnerable and traumatized 
children has the potential to both enable academic achievement and provide appropriate relationship experiences. Indeed, counseling and educational treatment is about providing opportunities for children to internalize valuable relationship experiences which they have previously been deprived of and achieve socially acceptable goals which might help them to build a more solid interpersonal identity based on successful learning acquirements (Tomlinson, 2004).

Through a stable and supporting framework, we hypothesized that this model provided the parents with the appropriate assistance to deal with a series of important, high distress provoking issues over a long period and in the child's different developmental stages. The work with P.'s family is exemplary of the complexities and the strict requirements of the intervention process that counselors, professionals, and medical services working in the area of families at risk therapy and disability face.

\section{CONCLUSIONS}

Given the extreme dependence of the child with CI on the parents' capacity to support its socialemotional development in our model a considerable place is conveyed to therapeutic/counseling techniques and processes that address couples' and families' relational and emotional dynamics.

Many times, disabled children's counselors are challenged by acute family and couple crises related to the trauma of the disability, to threats to the child's life, to everyday practical difficulties, and to the risks of social and school exclusion. Therefore, parents may find themselves in unmanageable situations experiencing extreme stress and thus risk displaying insufficient or unconstructive or even harmful responses.

Children's adequate psychosocial development and successful school inclusion are key challenges in the area of disability intervention (Miller, Recsky, \& Armstrong, 2004; Drotar, 2006; Georgiadi \& Kourkoutas, 2010). Children with CI usually have an extensive need for support on a number of aspects related to their physical and psychosocial functioning. Many professionals often get involved in this long-term and complex rehabilitation process in a way that is fragmented, disjointed, and unproductive for the child and its family (Kourkoutas, 2009). Traditional interventions based on the medical approach of disability and CI are criticized as being limited in the provision of effective psychosocial support (Turnbull et al., 2006). Many authors have advocated more holistic intervention models taking into consideration not only the rehabilitation requirements of the child but also the family's emotional experiences and psychosocial needs (Morison, Bromfield, \& Cameron, 2003). Individual counseling treatments which are not family oriented and based on specific theoretical model practices are also questioned for their efficacy in childhood disability.

In the counseling field, an increasing number of authors also advocate the adoption of more eclectic and integrative or pluralistic approaches (Goldenthal, 2005; Cooper \& McLeod, 2007; Smith, 2013).

The ecological approach, by taking into consideration all eventual risk or protective parameters affecting the psychosocial development of the child with the disability, helps family counselors to foster a global view (Zipper \& Simeonsson, 2004; Drotar, 2006).

Childhood illness may cause serious conflicts for the couple or reveal and inflate hidden and unexpressed dysfunctions of the couple or wider family, as well as personal shortcomings and problematic parental practices due to the acute and tremendous distress parents experience 
in cases of life-threatening childhood illnesses. Counselors very often find themselves in such critical situations without being well equipped to deal with them. Even though many of the theoretical models in the area of disability are practical solutions or family support focused, counselors should be trained to face and make use of these family crises in order to enhance parents' capacities for more effective management of their own relationships, their rearing practices, as well as their relations to the social environment.

Our case study, through family and school staff interviews, has revealed that "combined individual, parent-child, and family work that takes into consideration family dynamics, organization, and the child's needs and difficulties is more than necessary" according to the research counselor and both parents. In fact, the counseling process helped them to "counterbalance the impact of the "traumatic" incident" on the family and avoid being trapped in conflicting and "blind/stalemate" or "irrational reactions" despite the many critical phases and incidents they encountered.

In our case, counseling was offered for a range of issues (e.g., relationship problems, emotional disturbance, parenting concerns). In addition, a collaborative partnership (successful "working alliance") with the parents provided them with a stable relational framework which contains both emotional aspects/dimensions and practical ones; both of them can have a positive, even therapeutic (as P.'s mother and one of the teachers mentioned) effect on their way of behaving and treating the child.

In fact, an essential aspect of a counselor's/therapist's work with parents and teachers of children with CI consists mainly of his offering them "therapeutic ("intermediary") space" and "support" so they can "recreate the [ill/disordered] child in their mind," accept his deficits and limitations, and enhance his psychosocial skills.

In summary, our case study findings, in accordance with available evidence, show that when working with vulnerable, at risk children combined systemic and child-focused models are more effective than single-individual interventions (Carr, 2009). It has also been shown that interventions are much more effective when social skills (resilient perspective) training is provided for the children as well as training and counseling for the parents (Walsh, 2006).

The model of intervention seeks to minimize trauma symptoms and assist parents to develop more adaptive coping styles by rebuilding hope, strengthening resiliency, and regaining control of their lives. In addition, it is essential to help parents reconnect to support networks, and assist them to reframe their traumatic experiences and improve their relational patterns (Altschuler, 2011).

The value of preserving systemic thinking in childhood CI is largely recognized (Larner, 2009). Systemic thinking, combined with a psychodynamic approach, allows involved persons to express their inner voices and construct new narratives and meanings and to find new ways of relating with their child, the school, and themselves. Here what works in practice is seen as more relevant than strict adherence to a theory paradigm or position. It also fits research demonstrating that common factors such as the therapeutic relationship contribute more to therapeutic change than the specific model or technique used (Carr, 2009).

The following principles are essential in the counseling intervention and psychotherapeutic work with parents and children with disabilities or chronic illnesses in order to ensure the child attains full psychosocial and academic development and social-school inclusion:

- A respectful appreciation of parents' anxieties and concerns-their expectations for their children, their efforts to promote their child's psychosocial, and physical development; 
- Offer parents a new understanding of the sources of the child's distress, especially a greater appreciation of the child's anxiety, frustration, or discouragement and his/her coping strategies to manage such stress;

- An attempt to identify, and then ameliorate, ongoing patterns of family interaction that perpetuate painful emotions in the mind of the child, especially vicious cycles of criticism and defiance;

- Help parents understand the importance of reparative moments in the life of the child, and the need for parents to initiate this repair;

- Work with parents to find opportunities for responsiveness to their child's interests and to create more moments of positive affect-sharing in their daily interactions with their children;

- Consider the importance of involving fathers in the counseling process; and

- Teach and encourage proactive problem-solving and support for the child's pro-social behavior.

Overall, according to the research data, working with families and medical services or schools, integrating (individual and family) counseling in order to gain important insights into the family's and child's internal dynamics and development, with wider systemic intervention and eclectic techniques seems a critical dimension of effective practice

(Drotar, 2006; Altschuler, 2011; Sperry, 2014).

\section{NOTE}

1. Parents had the liberty to decide about the frequency of the counseling sessions, according to their needs. Counseling sessions were covered by the parents' insurance.

\section{REFERENCES}

Altschuler, J. (2011). Counselling and psychotherapy for families in times of illness and death. New York, NY: Palgrave Macmillan.

Carr, A. (2009). What works with children and adolescents and adults? A review of research on the effectiveness of psychotherapy. London, England: Routledge.

Cooper, M., \& McLeod, J. (2007). A pluralistic framework for counselling and psychotherapy: Implications for research. Counselling and Psychotherapy Research, 3, 135-143.

Crown, N. J. (2009). Parenting a child with disabilities. Personal reflections. Journal of Infant, Child, and Adolescent Psychotherapy, 8(1), 70-82.

Dempsey, S. (2008). Extreme parenting: Parenting your child with a chronic illness. London, England: J. Kingsley.

DeV. Peters, R., Leadbeater, B., \& McMahon, R. J. (2005). Resilience in children, families, and communities linking context to practice and policy. New York, NY: Kluwer.

Drotar, D. (2006). Psychological interventions in childhood chronic illness. Washington, DC: American Psychological Association.

Emde, R. N., \& Robinson, J. (2000). Guiding principles for a theory of early intervention: A developmentalpsychoanalytic perspective. In J. P. Shonkoff \& S. J. Meisels (Eds.), Handbook of early intervention (pp. 160-178). Cambridge, England: Cambridge University Press.

Fraser, M. W., \& Galinsky, M. J. (2004). Risk and resilience in childhood: Toward an evidence-based model of practice. In M. W. Fraser (Ed.), Risk and resilience in childhood: An ecological perspective (pp. 385-402). Washington, DC: NASW Press.

Georgiadi, M., \& Kourkoutas, E. (2010). Supporting pupils with cancer on their return to school: A case study report of a reintegration program. Social \& Behavioral Science, 5, 1278-1282. 
Goldenthal, P. (2005). Helping children and families. A new treatment model integrating psychodynamic, behavioural, and contextual approaches. Hoboken, NJ: John Willey.

Green, V. (2000). Therapeutic space for re-creating the child in the mind of the parents. In J. Tsiantis (Eds.), Work with parents (pp. 25-45). London, England: Karnac Books.

Hart, A., \& Blincow, D. (2007). Resilient therapy: Working with children and families. London, England: Routledge.

Kourkoutas, I. (2008). An ecosystemic psychodynamic intervention for children with mild psychosocial problems and academic difficulties: Prospects and limits of the evaluation process. In C. Canali, T. T. Vecchiato, \& J. K. Whittaker (eds.) Assessing the evidence-base of intervention for vulnerable children and their families (ch. 29). Padua, Italy: Fondazione Emanuela Zancan.

Kourkoutas, E. (2009). Family and disability. Interpersonal Acceptance Rejection, 1, 7-9.

Kourkoutas, E., Georgiadi, M., \& Plexousakis, S. (2010). Quality of life of children with chronic illnesses. A critical literature review. Procedia Social and Behavioural Sciences, 2(2), 4763-4767.

Kourkoutas, E., \& Xavier Raul, M. (2010). Counseling children at risk in a resilient contextual perspective: A paradigmatic shift of school psychologists' role in inclusive education, Social \& Behavioral Science, 5, 1210-19.

Larner, G. (2009). Integrative family therapy with childhood chronic illness: An ethics of practice, The Australian and New Zealand Journal of Family Therapy, 1, 51-65.

Maroda, K. J. (2010). Psychodynamic techniques. Working with emotions in the therapeutic relationship. New York, NY: The Guilford Press.

Miller, A. R., Recsky, M. A., \& Armstrong, R. W. (2004). Responding to the needs of children with chronic health conditions in an era of health services reform. JAMC, 171(11), 1366-1367.

Morison, J. M., Bromfield, L. M., \& Cameron, H. J. (2003). A therapeutic model for supporting families of children with a CI or disability. Child and Adolescent Mental Health, 3, 125-130.

Power, P. W., \& Dell Orto, A. E. (2004). Families living with CI and disability. Interventions, challenges, and opportunities. New York, NY: Springer.

Schmidt, N. R. (2010). Core principles of assessment and therapeutic communication with children, parents and families: Towards the promotion of child and family wellbeing. New York, NY: Routledge.

Seligman, M., \& Darling, R. B. (2008). Ordinary families, special children: A system approach to childhood disability (3rd ed.). New York, NY: Guilford Press.

Smith, G. (2013). Working with trauma: Systemic approaches. New York, NY: Palgrave Macmillan.

Sperry, L. (2014). Behavioral health. Integrating individual and family interventions in the treatment of medical conditions. New York, NY: Routledge.

Taylor, R. M., Gibson, F., \& Franck, L. S. (2008). The experience of living with a chronic illness during adolescence: A critical review of the literature. Journal of Clinical Nursing, 17(23), 3083-3091.

Tomlinson, P. (2004). Therapeutic approaches in work with traumatized children and young people: Theory and practice. London, England: Jessica Kingsley Publisher.

Turnbull, A., Turnbull, R., Erwin, E. J., \& Soodak, L. C. (2006). Families, professionals, and exceptionality: Positive outcomes through partnership and trust (5th ed.). Upper Saddle River, NJ: Merrill/Prentice Hall.

Vickers, M. H. (2006). Working and caring for a child with chronic illness. New York, NY: Palgrave Macmillan.

Walsh, F. (2006). Strengthening family resilience (2nd ed.). New York, NY: Guilford.

Wilson, S. (2003). Disability, counseling and psychotherapy. Challenges and opportunities. New York, NY: Palgrave Macmillan.

Zipper, I. N., \& Simeonsson, R. J. (2004). Developmental vulnerability in young children with disabilities. In M.W. Fraser (Ed.), Risk and resilience in childhood. An ecological perspective (pp. 161-182). Washington, DC: NAWS Press. 
Copyright of Journal of Infant, Child \& Adolescent Psychotherapy is the property of Routledge and its content may not be copied or emailed to multiple sites or posted to a listserv without the copyright holder's express written permission. However, users may print, download, or email articles for individual use. 